\title{
Automated Geometrical Evaluation of a Plaza (Town Square)
}

Machi Zawidzki

\author{
Department of Architecture, Massachusetts Institute of Technology \\ 77 Massachusetts Ave. 7-304G, Cambridge, MA 02139, USA
}

\begin{abstract}
This paper presents a method for an automated geometrical evaluation (AGE) intended as a design support tool for urban design of a plaza $(P)$. AGE is based on three normalized properties derived from a plan of $P$, namely: smallness, enclosure, and regularity. 19 worldwide plazas have been evaluated by 20 respondents in, what is called here, human subjective evaluation (HSE). A brief analysis of HSE including the identification of redundant categories is presented. Two $P$ evaluation methods based on all four $(S, C, E, R)$ and selected three $(S, E, R)$ properties are discussed. Good agreement of AGE based on $S, E$, and $R\left(N_{\text {SER }}\right)$ with HSE is shown. $P$ quality rating (excellent, good, fair) based on $\mathrm{NP}_{\mathrm{SER}}$ is introduced.
\end{abstract}

Exceptional cases are briefly discussed.

Keywords: urban design, public square, plaza, plan evaluation, design support tool.

\section{Introduction}

Plaza $(P)$, also known as a town square, civic center, city square, urban square, market square, public square, or piazza, is an open space of particular significance in urban design. For discussion on the multidisciplinary nature of urban design and the role of urban composition see the Introduction of [1]. The purpose of this paper is to answer the following question: "Is it possible to judge the quality of a plaza only by looking at its plan?". This work is a continuation of [1], but the current paper includes the following additional research:

- New thorough evaluation of the same nine Ps of Warsaw, Poland.

- Introduction of the additional ten worldwide Ps.

- New definition of the human subjective evaluation (HSE) based on normalized averaged values given in questionnaires.

- Brief analysis of HSE including the identification of redundant categories.

- New approach for $P$ evaluation based on the geometrical properties of its plan.

- Introduction of the new normalized geometrical properties of a $P$ : smallness $(S)$, compactness $(C)$, enclosure $(E)$, and regularity $(R)$.

- Two $P$ methods for automated geometrical evaluation (AGE) based on all four $(S, C, E, R)$ and selected three $(S, E, R)$ properties are discussed.

- Good agreement of AGE based on $S, E$, and $R\left(\mathrm{NP}_{\mathrm{SER}}\right)$ with HSE is shown.

- P quality rating (excellent, good, fair) based on $\mathrm{NP}_{\mathrm{SER}}$ is introduced.

- Exceptional cases are briefly discussed. 


\section{Human subjective evaluation of 19 worldwide plazas}

The original paper [1] concerned with nine Ps from Warsaw, Poland. Figure 1 shows the four most highly valued $P$ s.

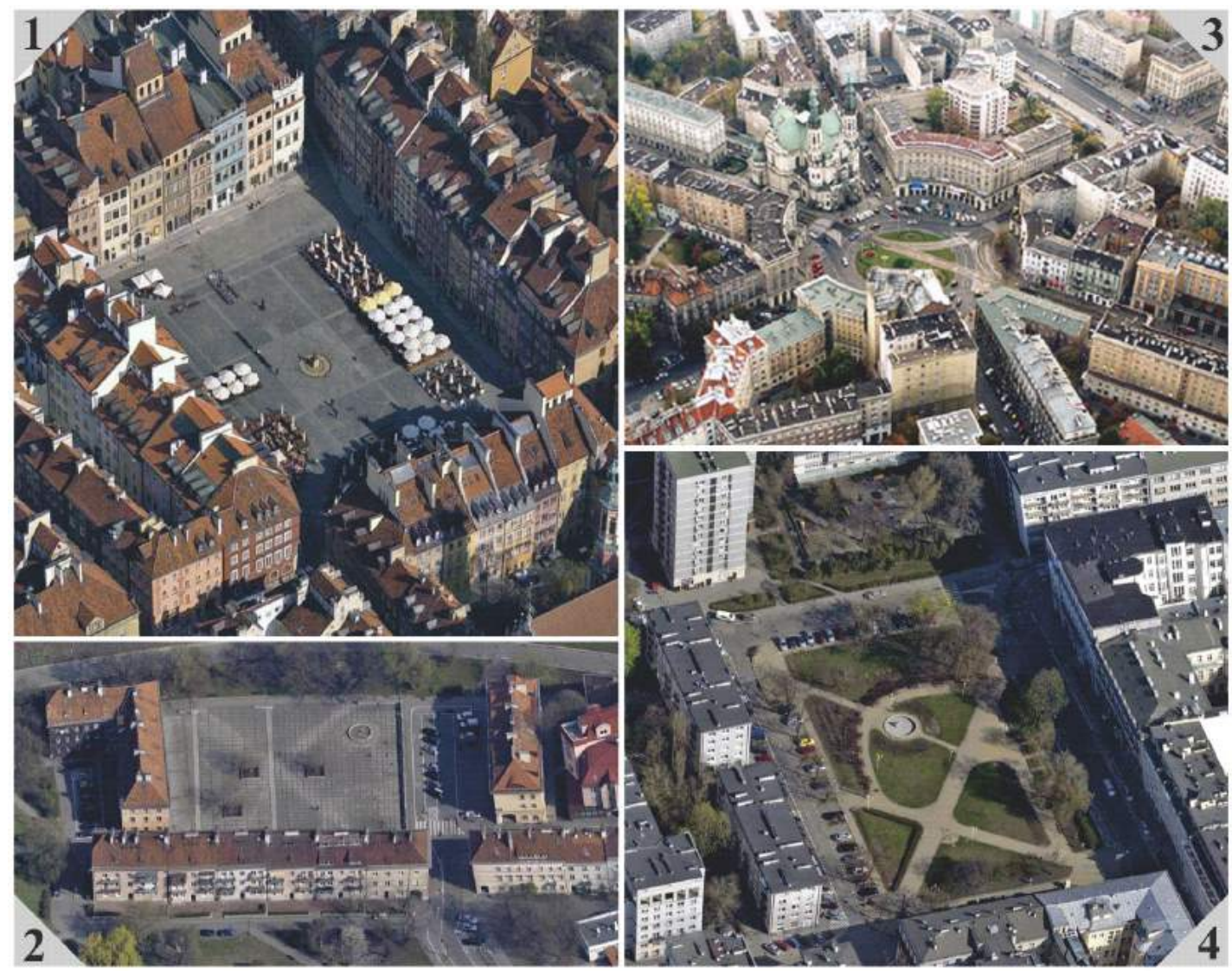

Figure 1: 1) Old Town Market, 2) Mariensztat, 3) Savior Sq., 4) Dąbrowski Sq.

Figure 2 shows the rest of Warsaw Ps. 


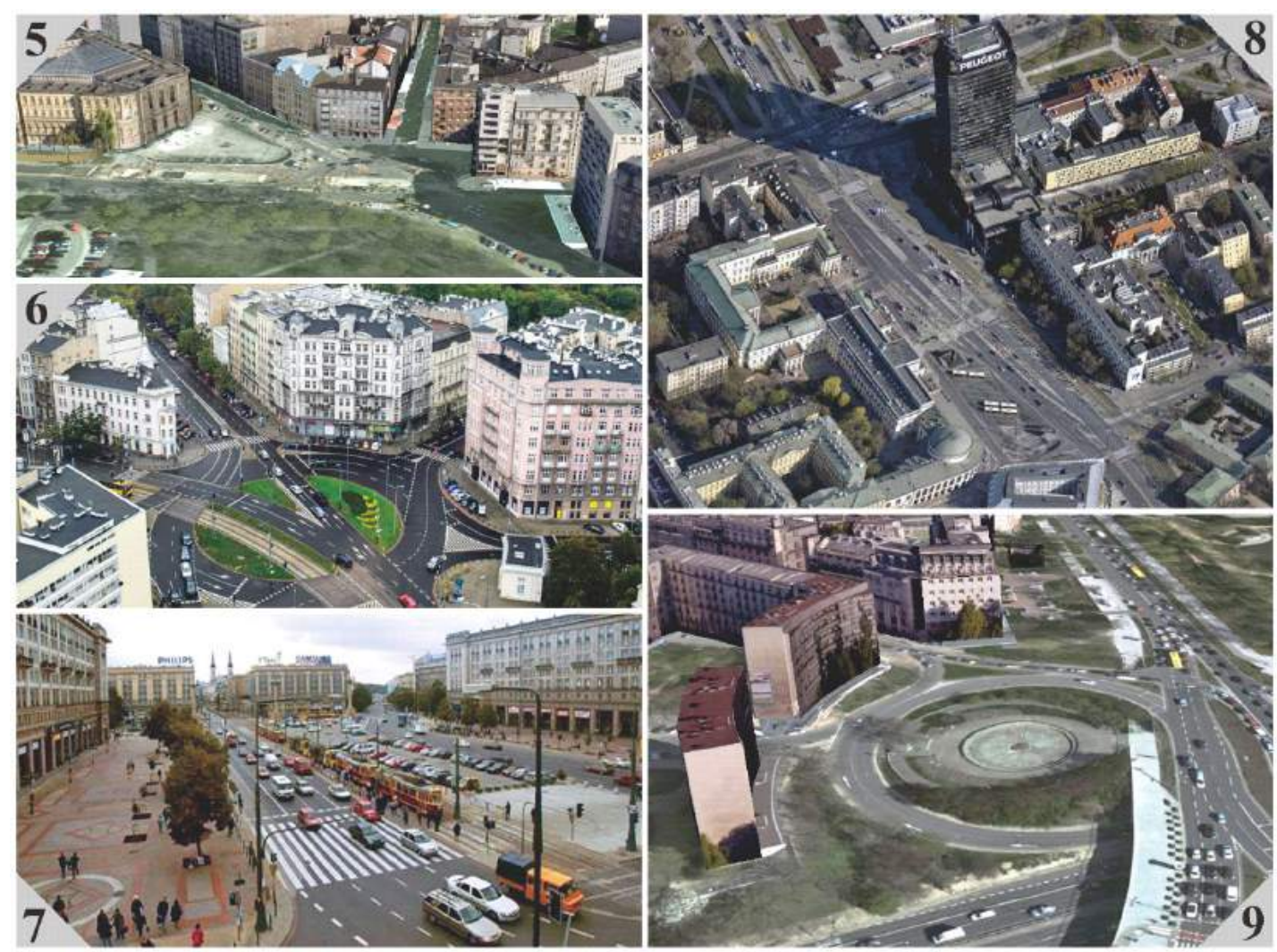

Figure 2: 5) Politechnika Sq., 6) Union of Lublin Sq., 7) Constitution Sq., 8) Bank Sq., 9) Crossroads Sq.

For further detail on these $P_{\mathrm{s}}$, including brief historical information see [1]. This paper re-evaluates these nine $P \mathrm{~s}$, and also considers ten worldwide $P$ s shown in Figures 3 and 4. 


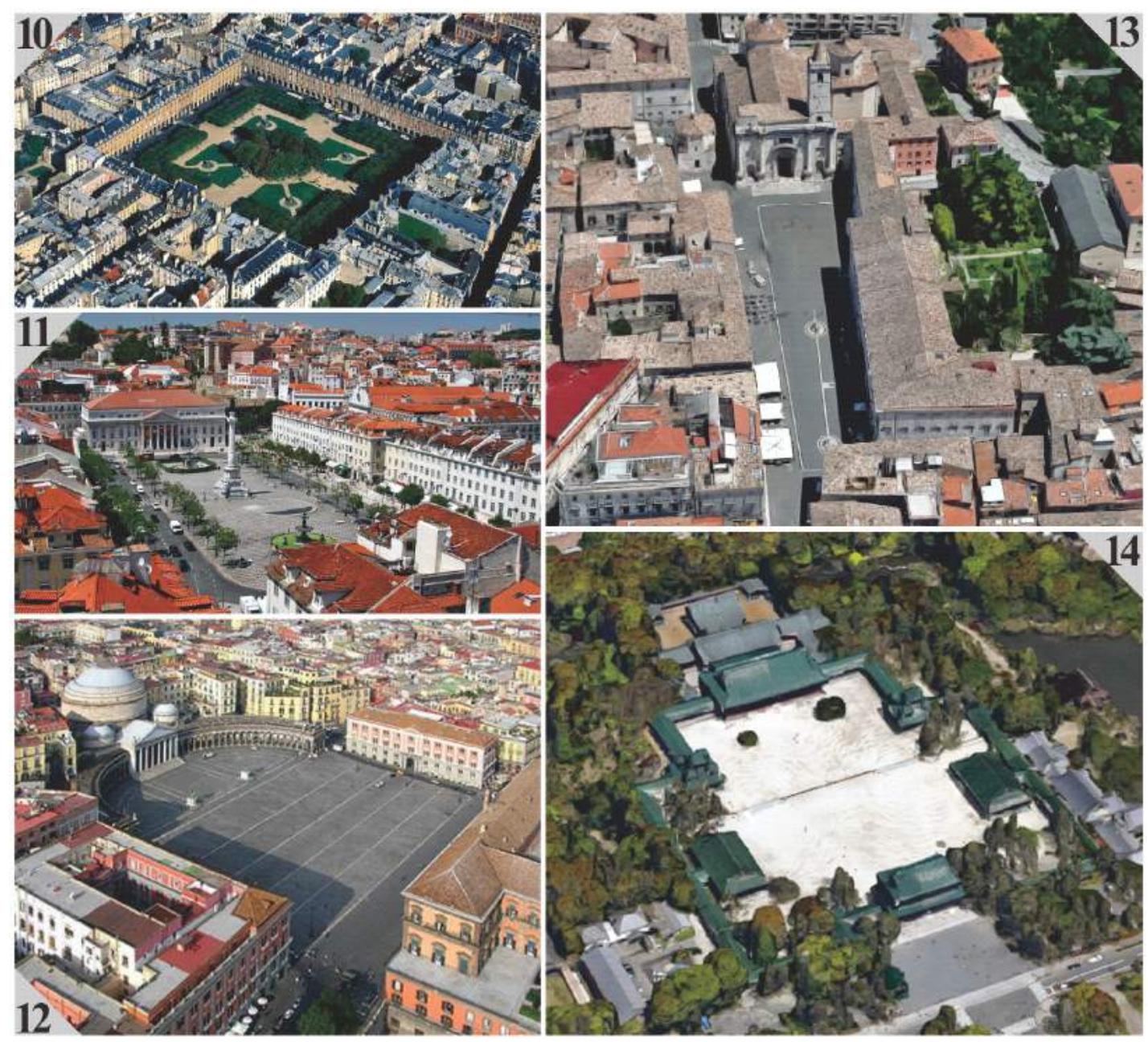

Figure 3: 10) Place des Vosges, Paris, France; 11) Praca Dom Pedro IV, Lisbon, Portugal; 12) Piazza del Plebiscito, Naples, Italy; 13) Piazza Arringo, Ascoli Piceno, Italy; 14) Heian Jingu, Kyoto, Japan 


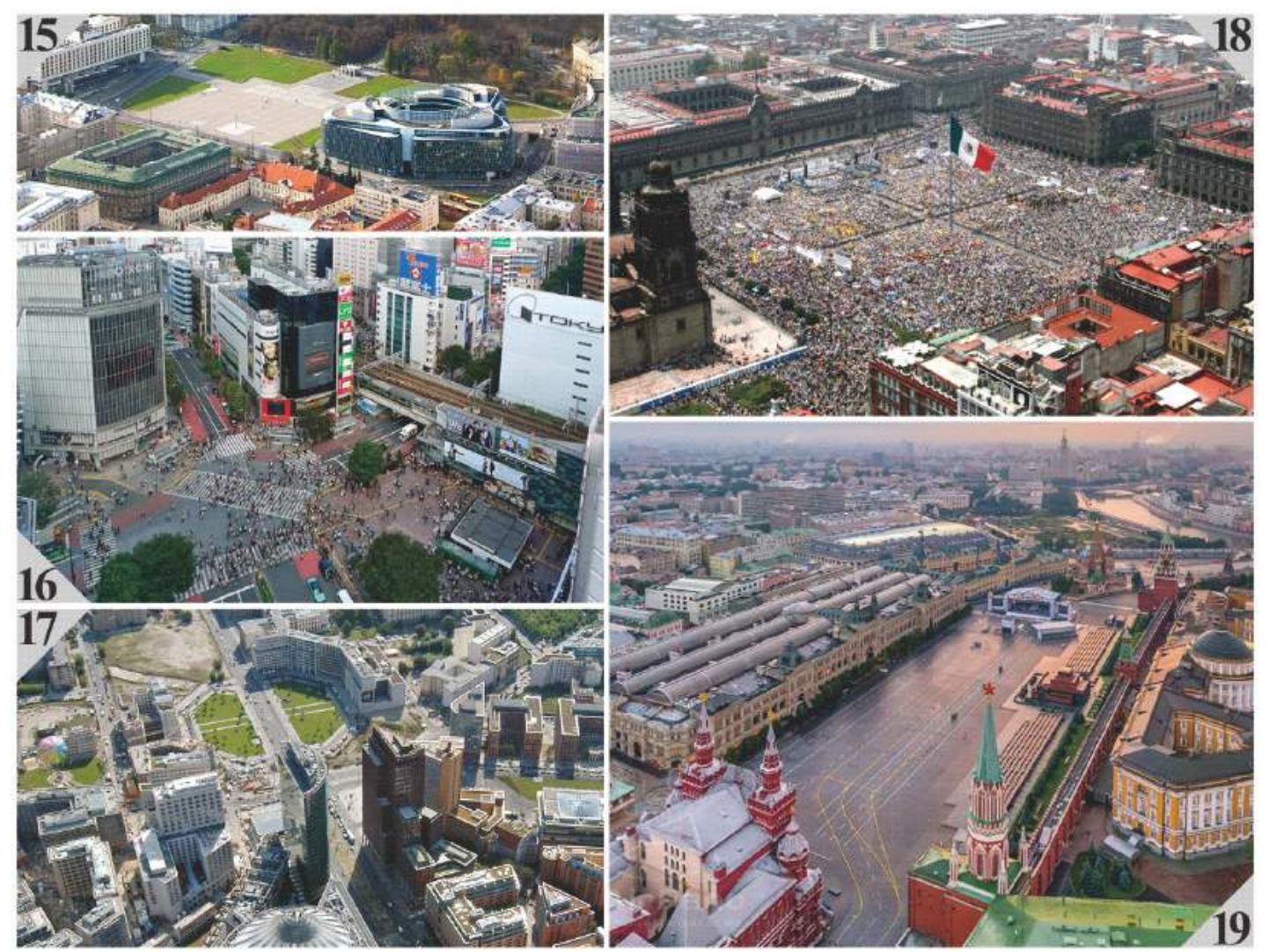

Figure 4: 15) Pilsudski Sq., Warsaw Poland; 16) Shibuya, Tokyo, Japan; 17) Potsdamer Platz, Berlin, Germany; 18) Zocalo, Mexico City, Mexico; 19) Red Square, Moscow, Russia.

20 respondents evaluated all $19 P_{\mathrm{S}}$ using the same questionnaire as in [2]. 15-bipolar pairs of adjectives and the semantic scale used in the evaluation is shown in Table 1. The questionnaire has been slightly modified to reflect better the needs of the experiment as explained below. 
Table 1: The questionnaire for human subjective evaluation (HSE) of a plaza.

\begin{tabular}{|r|r|r|r|r|l|l|l|l|l|}
\hline 1 & Dull & -3 & -2 & -1 & 0 & 1 & 2 & 3 & Dynamic \\
\hline 2 & Repelling & -3 & -2 & -1 & 0 & 1 & 2 & 3 & Attractive \\
\hline 3 & Chaotic & -3 & -2 & -1 & 0 & 1 & 2 & 3 & Arranged \\
\hline 4 & Artificial & -3 & -2 & -1 & 0 & 1 & 2 & 3 & Natural \\
\hline 5 & Boring & -3 & -2 & -1 & 0 & 1 & 2 & 3 & Interesting \\
\hline 6 & Disturbing & -3 & -2 & -1 & 0 & 1 & 2 & 3 & Comforting \\
\hline 7 & Cacophonous & -3 & -2 & -1 & 0 & 1 & 2 & 3 & Harmonious \\
\hline 8 & Dysfunctional & -3 & -2 & -1 & 0 & 1 & 2 & 3 & Functional \\
\hline 9 & Tense & -3 & -2 & -1 & 0 & 1 & 2 & 3 & Relaxed \\
\hline 10 & Unsocial & -3 & -2 & -1 & 0 & 1 & 2 & 3 & Social \\
\hline 11 & Harsh & -3 & -2 & -1 & 0 & 1 & 2 & 3 & Cozy \\
\hline 12 & Uninspiring & -3 & -2 & -1 & 0 & 1 & 2 & 3 & Inspiring \\
\hline 13 & Plain & -3 & -2 & -1 & 0 & 1 & 2 & 3 & Diverse \\
\hline 14 & Flimsy & -3 & -2 & -1 & 0 & 1 & 2 & 3 & Sound \\
\hline 15 & Inaccessible & -3 & -2 & -1 & 0 & 1 & 2 & 3 & Accessible \\
\hline
\end{tabular}

In calculations of the collective responses, the values have been assigned to the positive qualities of a $P$ (indicated by green in Table 1 ), called simply qualities from now on.

The major differences between the approach presented here and in [2] are:

- The smaller group of respondents: 20 persons instead of 300 .

- The evaluation has been performed by virtual exploration using Google Earth, instead of evaluating photographs .

- The focus was not on the aesthetic aspects of the $P_{\mathrm{s}}$, but on the spatial perception of a place.

The values of responses have been averaged into the "matrix of plazas" $(M P)$, that is 19 15-dimensional vectors. Next, $M P$ has been transposed into the "matrix of qualities" $(M Q)$, that is 1519 -dimensional vectors. The correlations among all vectors of $M Q$ have been calculated, which indicated that some responses are nearly equivalent. Two pairs of qualities, that is "Natural" \& "Relaxed" and "Comforting" \& "Cozy" had correlations of 0.88 and 0.86 , respectively. Therefore "Relaxed" and "Comforting" have been removed from the list of considered qualities.

The averaged values of responses for each $P$ have been summed and rescaled to the range $(0,1)$. This measurement of plaza's quality is called here "normalized accumulated quality”, NAQ for short. Table 2 shows the respondents' evaluations of all Ps sorted according to NAQ. 
Table 2: 9 HSE: Ps sorted according to NAQ, shown in the middle of each graph. For each $P$ all 20 evaluations by individual respondents and the mean of these evaluations are shown in gray and black, respectively.

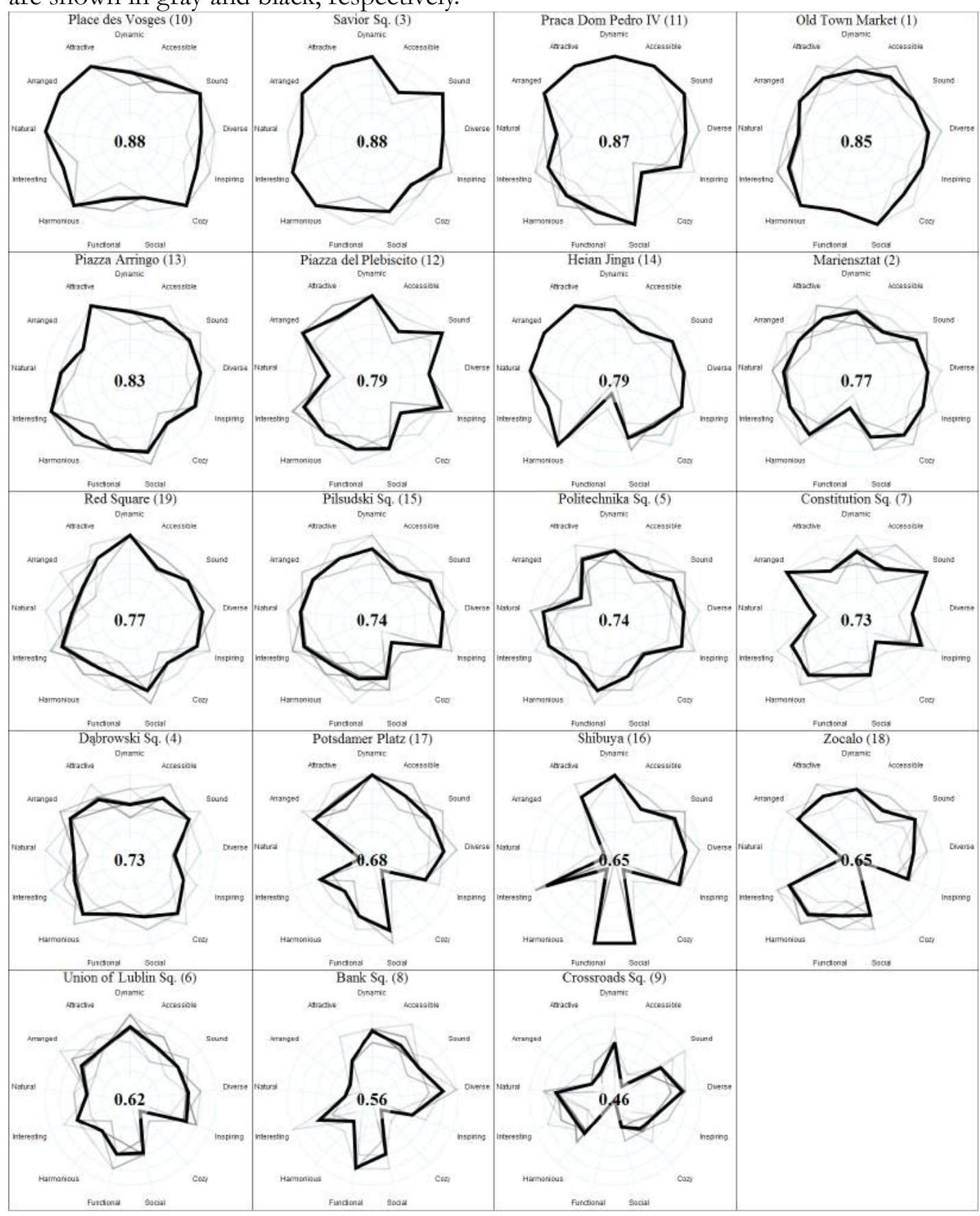

\section{Geometrical properties derived from a plaza's plan}

As mentioned in the Introduction, the aim of this work is to assess the quality of a $P$ by analysis of its plan, in other words - an automated geometrical evaluation (AGE) of a P. Although [3] claims that "aesthetics is a more important consideration in urban design than 
legibility", this study focuses on fundamental geometric properties of a P's plan, disregarding its aesthetic aspects: “(...) just as there are furnished and empty rooms, so one might also speak of furnished and unfurnished plazas (...)" [4].

In this paper, four geometrical properties (called simply properties from now on) of a $P$ have been identified: smallness, compactness, enclosure and regularity. They have been formulated to match common human perception as described in the following subsections.

\subsection{The smallness of a plaza}

The size is a fundamental geometrical property of a $P$. According to Camilo Sitte's classic book on urban design [4], "A plaza that is too small usually does not give due effect to monumental buildings; on the other hand, one that is too large is, obviously, still more awkward (...). Such giant squares of vast dimensions occur in modern cities almost solely as drill grounds". A straightforward measurement describing $P^{\prime}$ s size is its surface area. The above citation indicates that in general, the relationship between the size and NAQ of a $P$ is not straightforward. However, according to the respondents' opinions regarding the considered 19 Ps, which size range from medium to very large, it has been observed that the largeness is perceived negatively. Therefore, the areas have been rescaled to the sizes of two arbitrarily chosen Ps. The first one, that is the smallest, is Mariensztat $\left(P_{2}\right)$, shown in Figure 1.2. The area of $P_{2}$ is approximately $4,500 \mathrm{~m}^{2}$, which is within suggested range for an "ideal plaza" [5]. The largest is Zocalo $\left(\mathrm{P}_{18}\right)$, shown in Figure 4.18 , with the area of $57,600 \mathrm{~m}^{2}$. It has been chosen as a referential maximum, because it is indeed very large, but still has a simple and well defined form. Although a number of larger public squares exist, they are not perceived as coherently designed enclosed spaces any more. They may have strict geometrical shapes in plan, but do not form proper plazas usually due to the lack of height of the surrounding buildings. In other words, such enormous public squares are "open spaces" rather than actual plazas. For the list of such examples see [6]. Thus the notion of smallness $(S)$ has been defined, as follows:

$$
S(P)=1-\frac{A_{P}-A_{P 2}}{A_{P 18}-A_{P 2}}
$$

\subsection{Compactness}

Area-perimeter ratios are often used to quantify $2 \mathrm{D}$ shape compactness (C). Usually compactness $C^{\prime}$ of a shape $s$ of perimeter $L$ and area $A$ is defined as follows [7]:

$$
C^{\prime}(s)=\frac{L^{2}}{A}
$$

Compactness defined in such a way is dimensionless and minimized by a disk [8]. However, in the study presented here, it is more practical to assume an inverted definition of compactness $(C)$, so it is actually maximized by a disk. Additionally it has been rescaled to the range $\{0,1 / 4 \pi\}$. 


$$
C(P)=4 \pi \frac{A_{P}}{L_{P}^{2}}
$$

For alternative area-perimeter ratios for measurement of 2D shape compactness see [9].

\subsection{Enclosure}

In the same publication [4] Sitte points out emphatically: "the main requirement for a plaza is the enclosed character of its space". In this paper, so called, enclosure $(E)$ is derived directly from a P's plan, as explained in Figure 5.

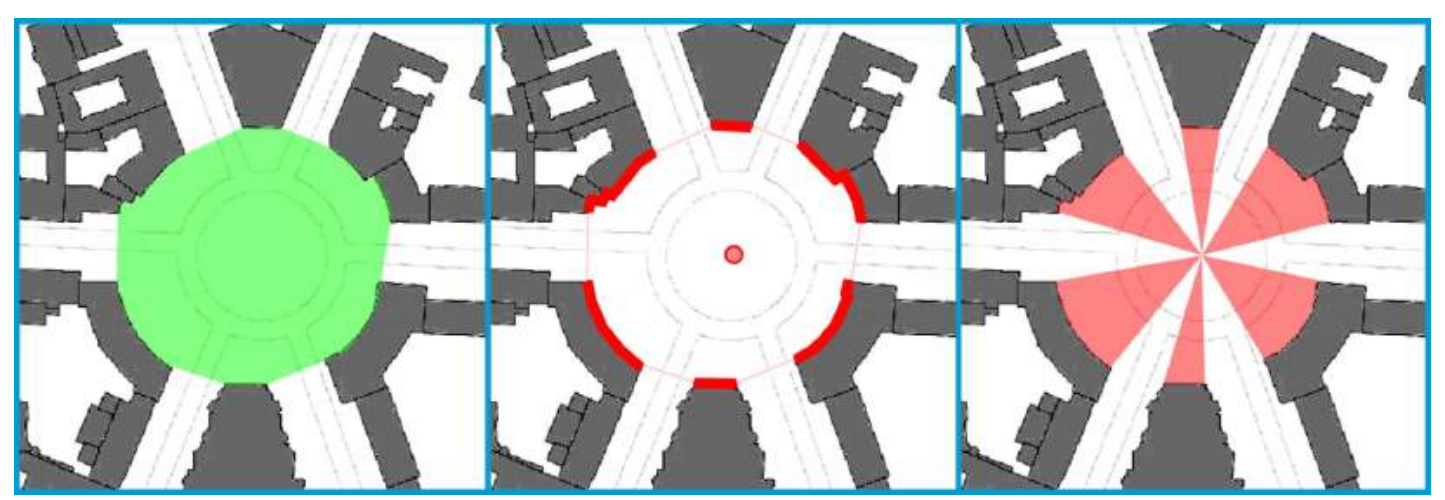

Figure 5: 1) Identification of a $P$ and its perimeter. Calculation of the total area of a $P$, shown in green. 2) Identification of the building facades which define the $P$ and $P$ 's center, shown as thick red lines and a dot, respectively. If a $P$ does not have a clearly defined center - a centroid of the perimeter is calculated. 3) The area of sectors projected on the aforementioned facades is calculated and divided by the total area.

The enclosure does not require rescaling as it naturally ranges from 0 to 1 , for fully open, and fully enclosed spaces, respectively.

\subsection{Regularity}

Regularity is an intuitive quality in human perception of a shape. However, strict mathematical measurement of shape's regularity seems still problematic. Algorithms for detection of regular polygons for traffic sign recognition based on analysis of given photographs have been presented in [10] and [11]. However, the traffic signs are always convex, thus the focus of research is on the regularity of such shapes $[12,13]$. In this paper the regularity is assessed by assigning arbitrarily a real value from 0 to 5 , where 0 represents extremely irregular (e.g. $P_{16}$ shown in Figure 4.16) and 5 represents extremely regular (e.g. $P_{10}$ shown in Figure 3.10) shapes. Regularity is also rescaled to this range $(0$, $5)$.

Tables 3 and 4 collect the aforementioned geometrical properties for all Ps. 
Table 3: Smallness $(S)$, compactness $(C)$ enclosure $(E)$, and regularity $(R)$ calculated for Ps corresponding to Figures 1 and 2.

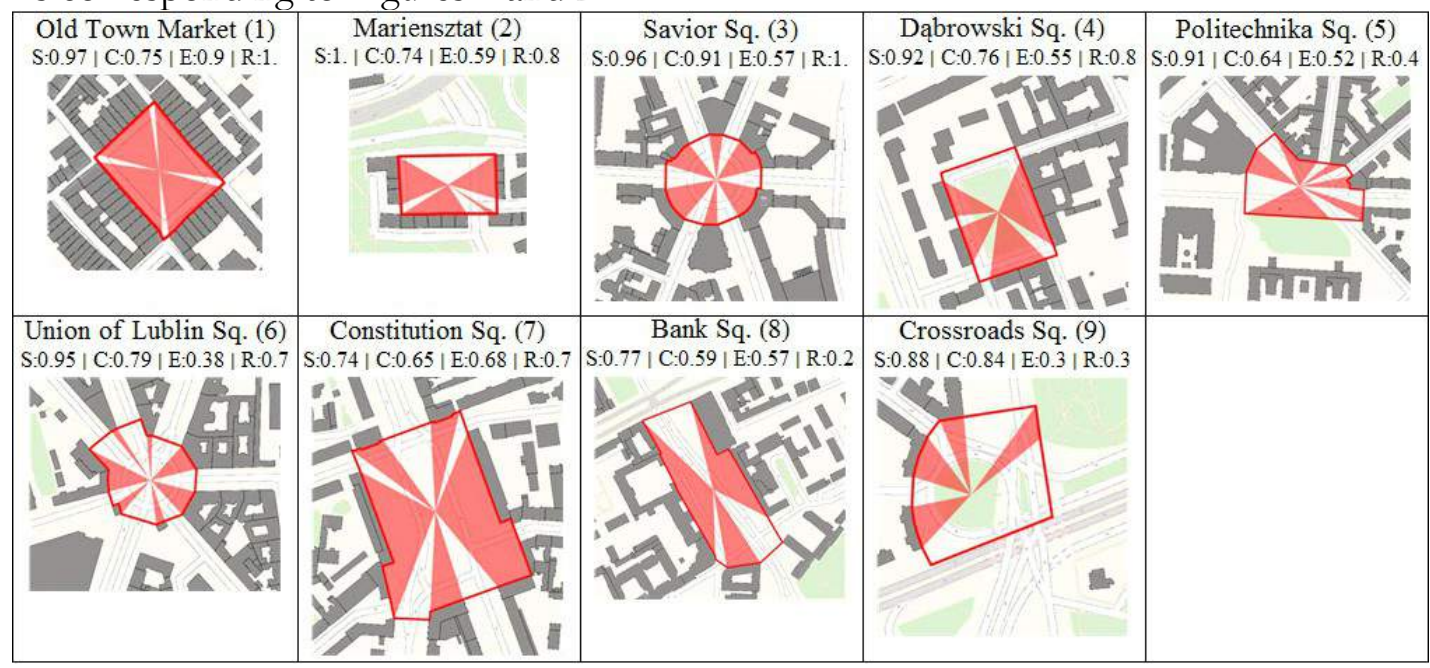

Table 4: S, C, E, and $\mathrm{R}$ calculated for Ps corresponding to Figures 3 and 4.

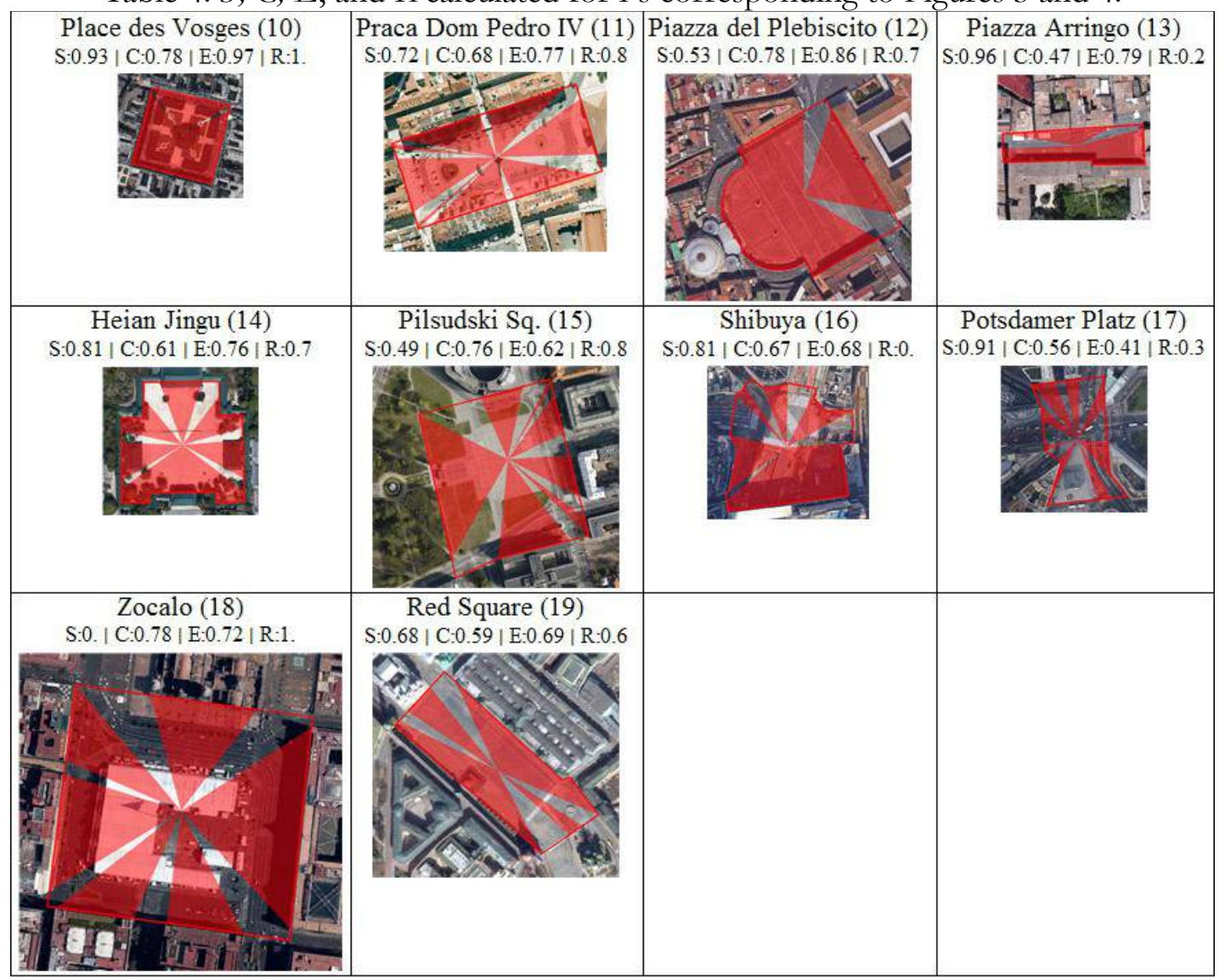

\section{Correlations between NAQ and geometrical properties of the plazas}


Table 5 shows correlations between NAQ of $P$ s and four properties described in subsections $3.1-3.4$.

Table 5: Correlations between $N A Q$ (rows) and properties calculated from $P$ s plans (columns). The color of the fitting line reflects the degree of the correlation, from red for the weakest, to cyan for the strongest. Qualities with weak correlation to properties are indicated by red frames.

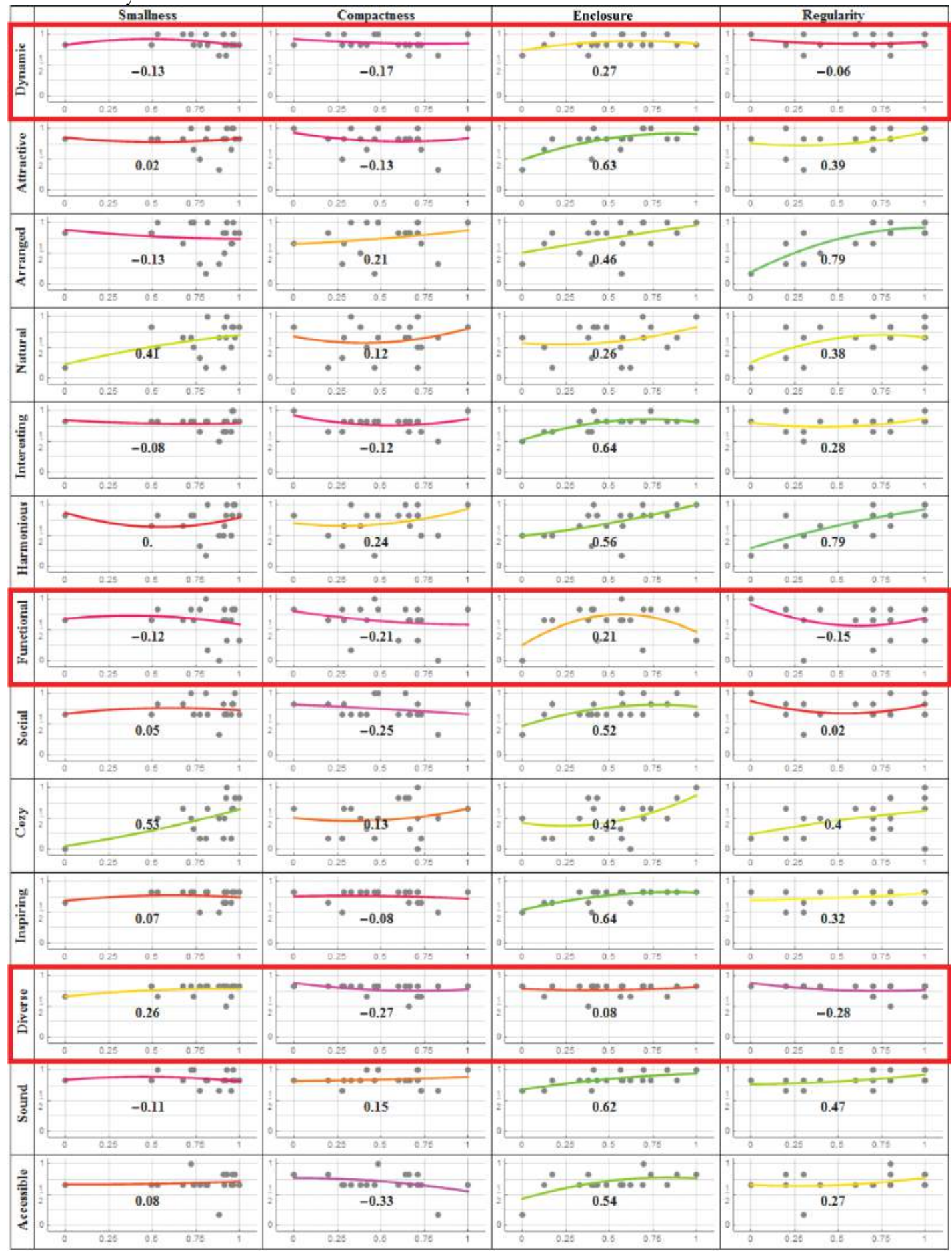


As Table 5 indicates, there are three qualities, "dynamic", "functional", and "diverse", which have weak correlation to all properties. Although they might be meaningful for more sophisticated models, in the one presented here they are not relevant, and therefore will be omitted.

Plazas' NAQs have been compared to normalized properties (NP). For validation, the plazas have been grouped into three sets: Warsaw plazas $\left(P_{1} \ldots P_{9}\right)$, worldwide plazas $\left(P_{10} \ldots P_{19}\right)$, and all plazas. The results are shown in Tables 6-8.

Table 6: Plazas $P_{1}$ to $P_{9}$. Top row: NAQ (Y axis) related to the individual NP (X axis). Bottom row: the same NAQ related to normalized accumulated all four and selected three properties. The color convention of the fitting lines as in Table 5.

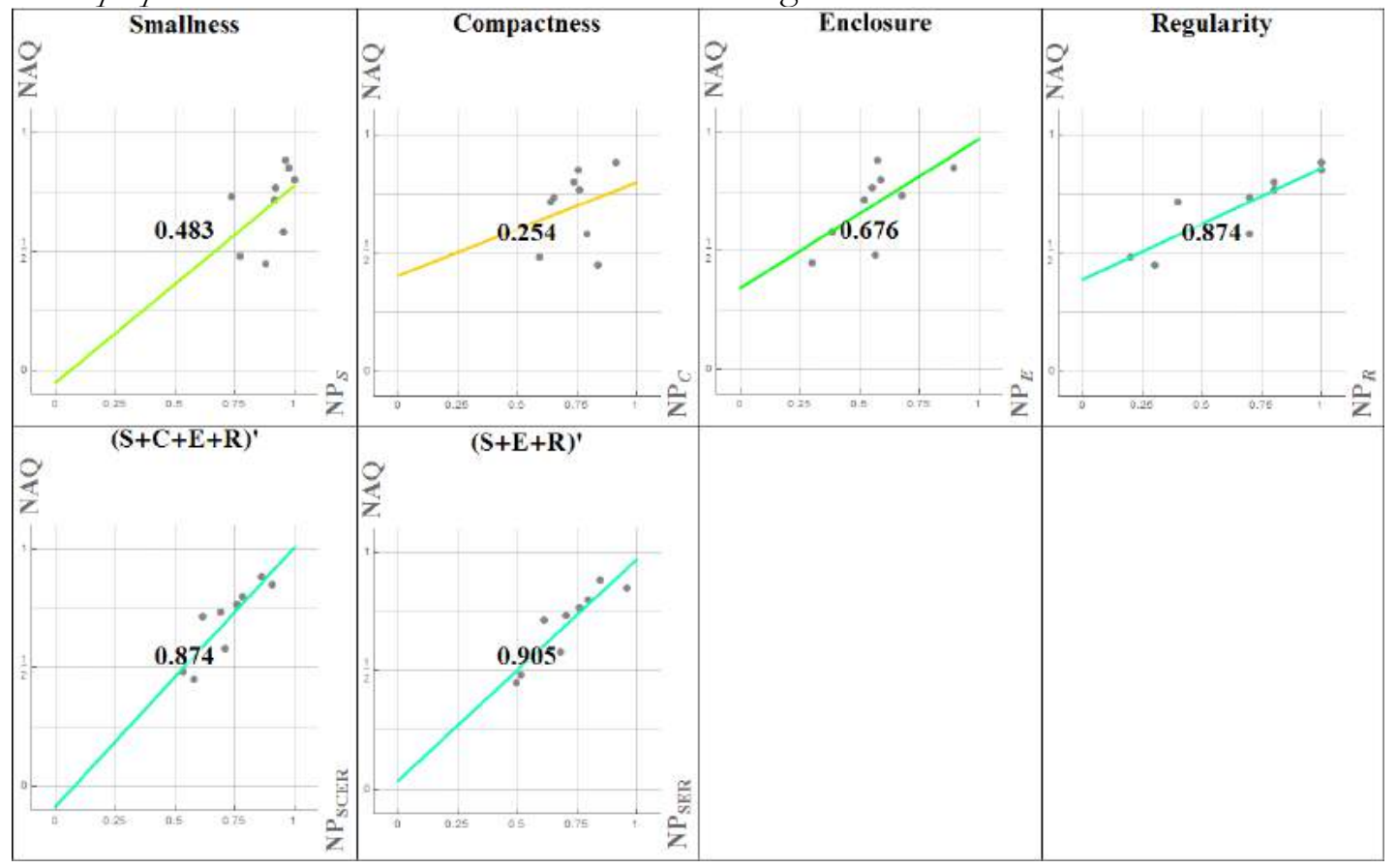

As Table 6 indicates, for these nine plazas, smallness $\left(\mathrm{NP}_{\mathrm{S}}\right)$, compactness $\left(\mathrm{NP}_{\mathrm{C}}\right)$, enclosure $\left(\mathrm{NP}_{\mathrm{E}}\right)$, and regularity $\left(\mathrm{NP}_{\mathrm{R}}\right)$ show rather good, poor, good, and very good correlations with NAQ, respectively. Simple summation of all these properties (NPSCER) is neutral to this correlation. However, exclusion of the compactness in this summation $\left(\mathrm{NP}_{\mathrm{SER}}\right)$ results in the best correlation with NAQ. 
Table 7: Plazas $P_{10}$ to $P_{19}$.

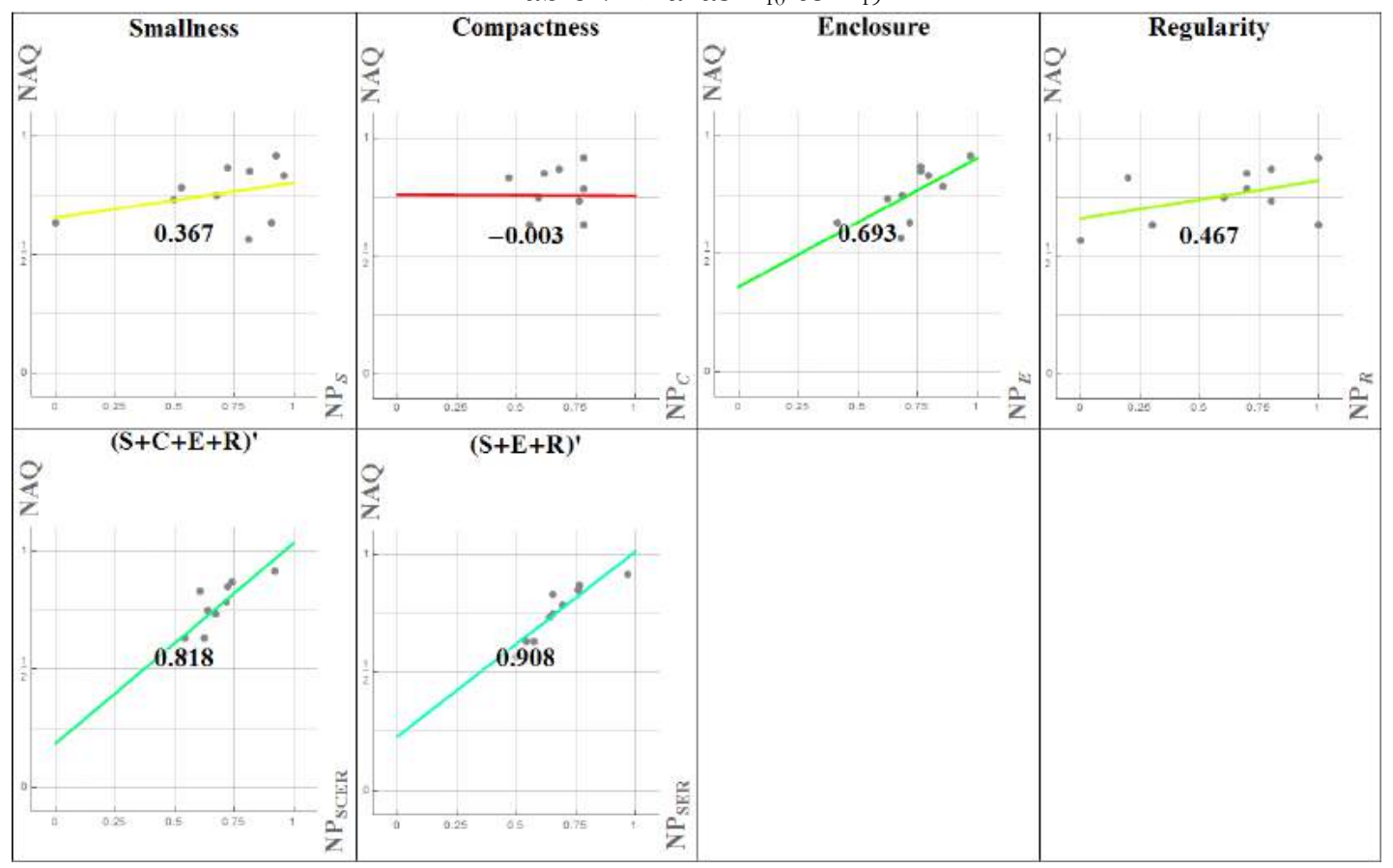

As Table 7 indicates, for these ten plazas, $\mathrm{NP}_{\mathrm{S}}, \mathrm{NP}_{\mathrm{C}}, \mathrm{NP}_{\mathrm{E}}$, and $\mathrm{NP}_{\mathrm{R}}$ show fair, very poor, very good, and rather good correlations to NAQ, respectively. $\mathrm{NP}_{\text {SCER }}$ and $\mathrm{NP}_{\text {SER }}$ have improved and much improved correlations with NAQ, respectively.

Table 8: Plazas $P_{1}$ to $P_{19}$.

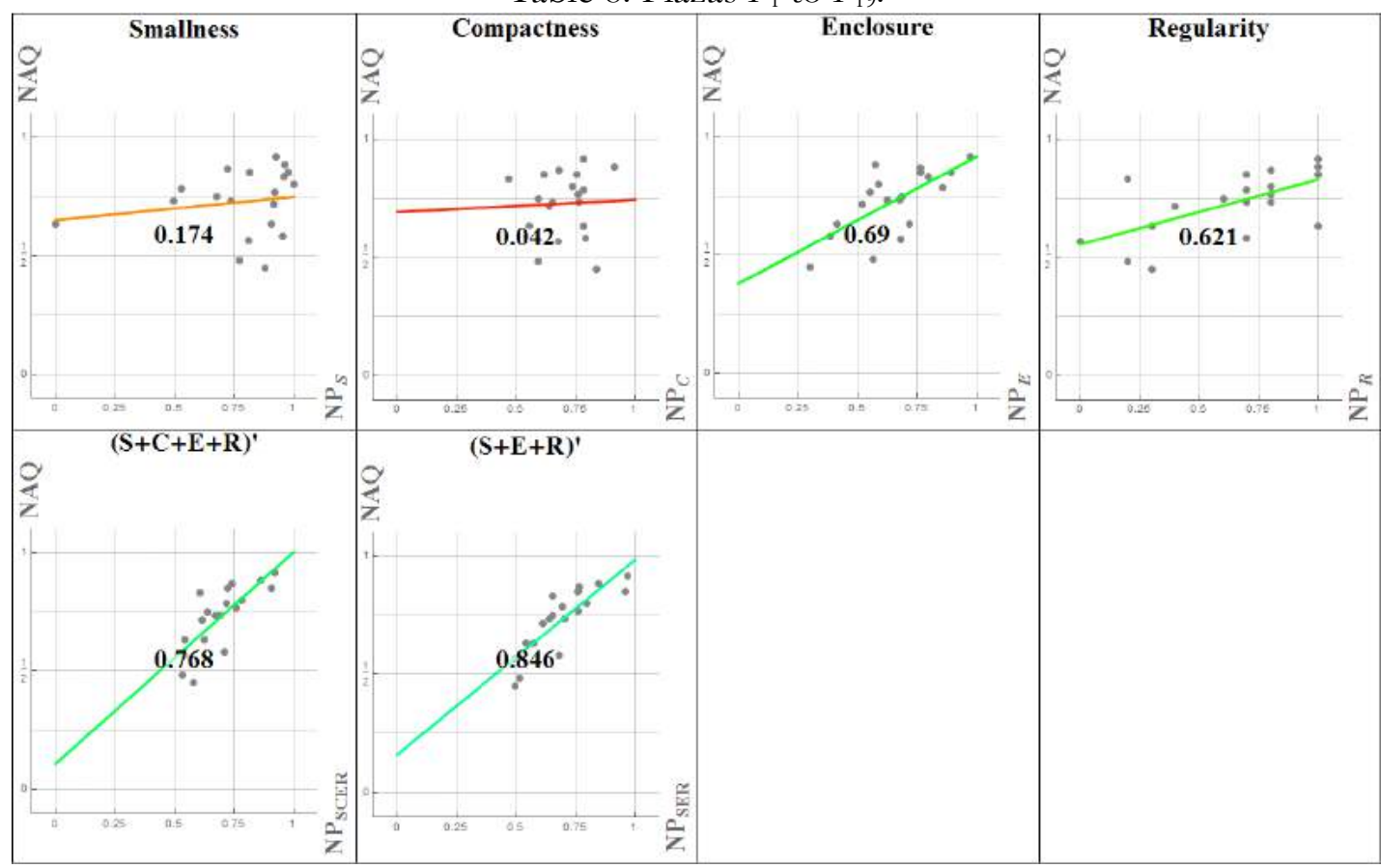

As Table 8 indicates, for all 19 plazas, $\mathrm{NP}_{\mathrm{S}}, \mathrm{NP}_{\mathrm{C}}, \mathrm{NP}_{\mathrm{E}}$, and $\mathrm{NP}_{\mathrm{R}}$ show poor, nil, good, and good correlations to NAQ, respectively. 
As in the previous cases, $\mathrm{NP}_{\mathrm{SCER}}$ and $\mathrm{NP}_{\mathrm{SER}}$ have improved and much improved correlations to NAQ, respectively.

As Tables 6-8 indicate, the correlations among qualities and properties, in various sets of plazas, although varying to certain degree, are rather consistent. Compactness seems not to contribute to this linear model.

\subsection{The correlation between HSE and AGE for the ten worldwide plazas}

In this subsection the correlation between human subjective evaluation (HSE) measured by NAQ and automated geometrical evaluation (AGE) measured by NP shows the relationship between NAQ and $\mathrm{NP}_{\text {SER }}$ for all 19 plazas. The plazas have been ordered according to NAQ.

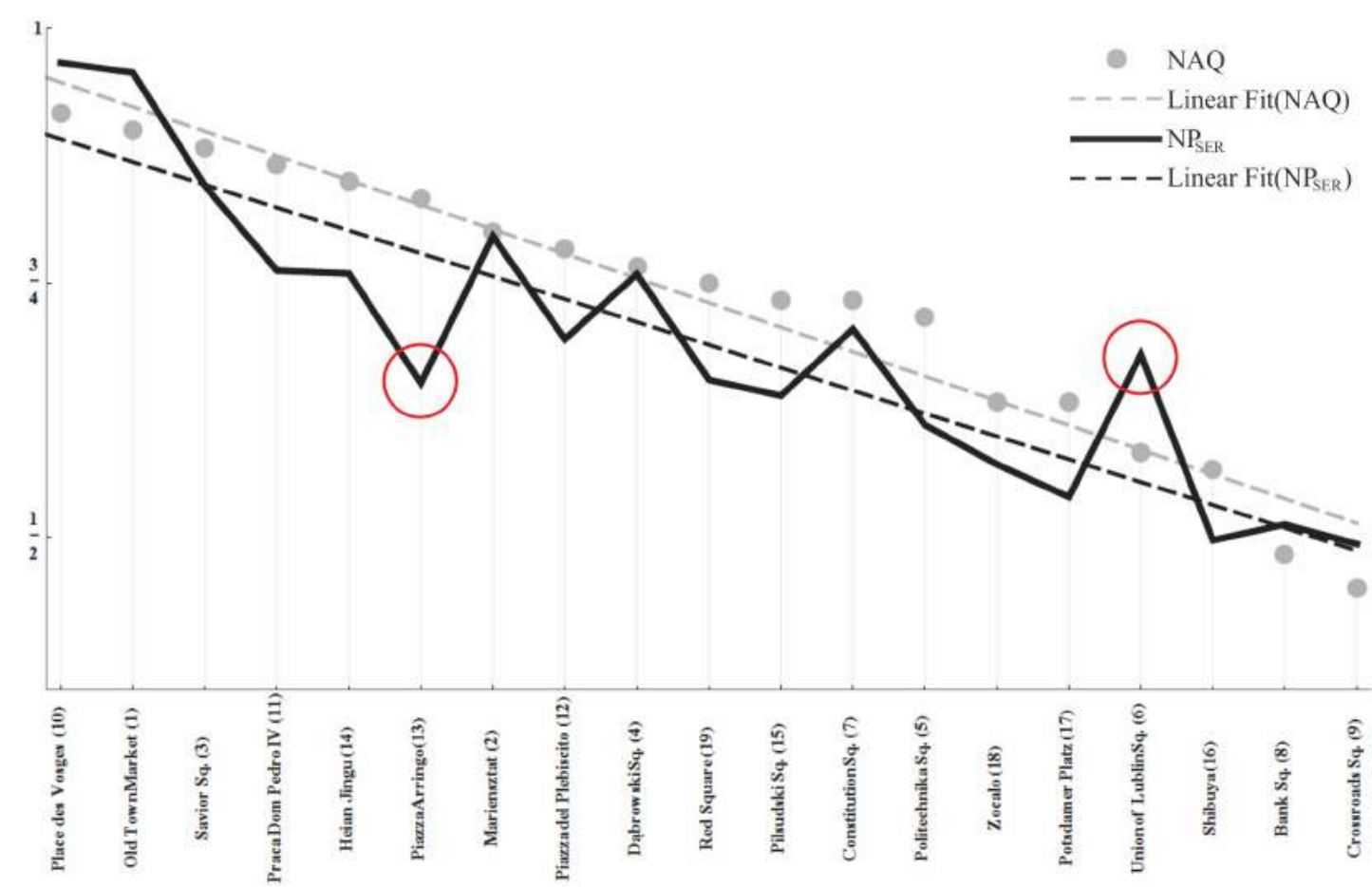

Figure 6. NAQ and $\mathrm{NP}_{\mathrm{SER}}$ for all 19 plazas ordered according to NAQ. The exceptional (outlying) cases, indicated by red circles, are commented in Table 9.

As Figure 6 indicates, the simple linear model $\left(\mathrm{NP}_{\mathrm{SER}}\right)$ shows rather good agreement with NAQ. Figure 7 shows how NP $\mathrm{NER}_{\text {R }}$ evaluates the 19 Ps and how these values correspond to respective NAQs. 


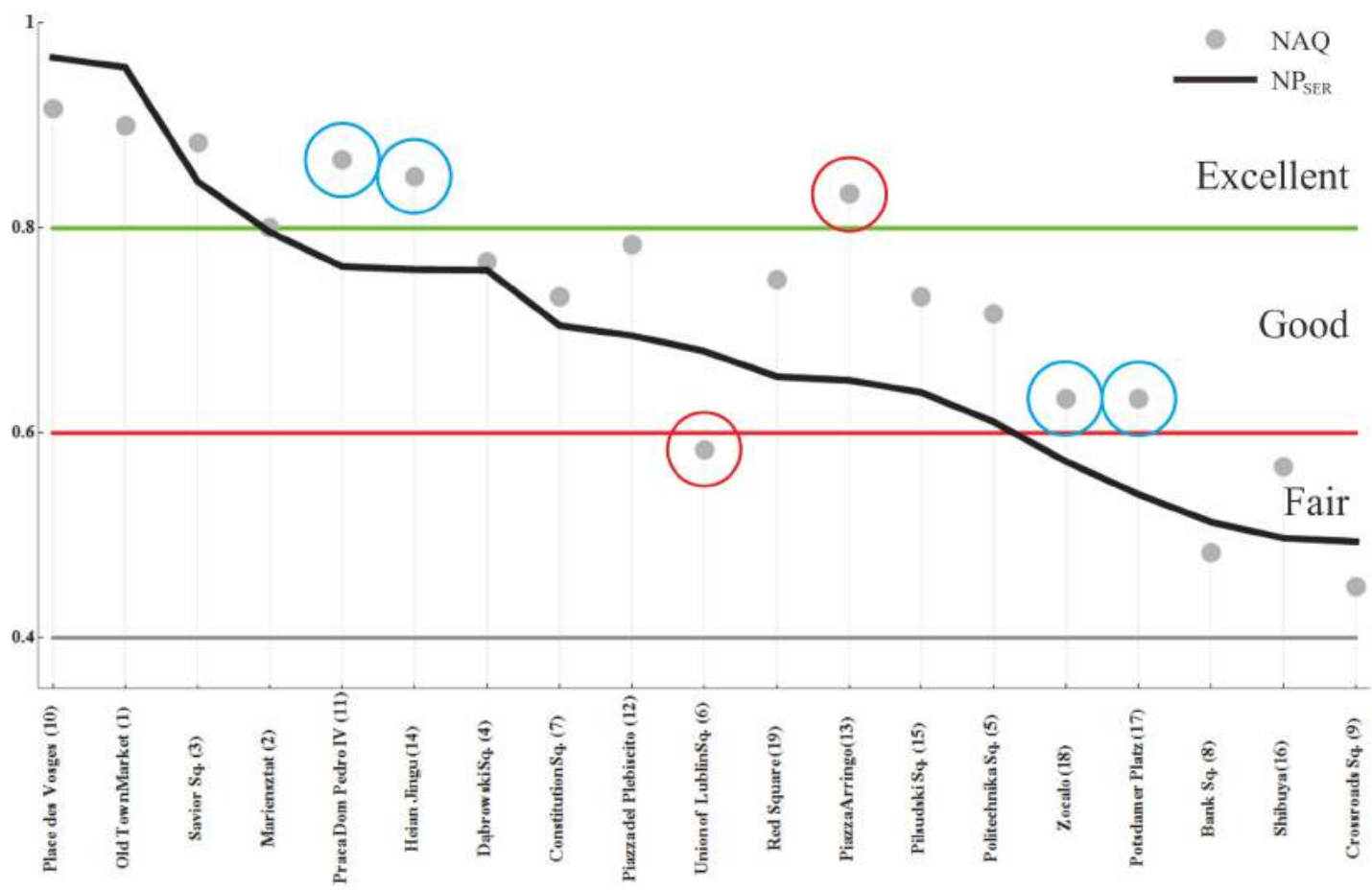

Figure 7. Arbitrary three ranges of $\mathrm{NP}_{\mathrm{SER}}$ values indicating excellent, good and fair plazas. The two exceptional cases shown in Figure 6 are also indicated here by red circles. Additionally, four cases of Ps "overly appreciated" by NAQ are indicated by cyan circles. All outlying cases are commented in Table 9.

As Figure 7 indicates, there are six cases where $\mathrm{NP}_{\text {SER }}$ misclassified plazas. In five cases, NAQ gave substantially higher rating than direct analysis of a plaza's plan by AGE. In one case, the reverse was true. The discrepancy of the former comes from the fact that those plazas are located in extremely attractive locations and/or themselves are extremely attractive architecturally. In the latter case, the substantial under-appreciation by NAQ also comes from the location and its traffic conditions. Table 9 collects comments regarding these outlying cases. Red indicates the case where a $P$ is viewed lower than $\mathrm{NP}_{\mathrm{SER}}$ suggests, while green indicates the opposite.

Table 9: The outlying cases

\begin{tabular}{|c|l|l|l|}
\hline P no. & NAQ & $\mathbf{N P}_{\text {SER }}$ & \multicolumn{1}{c|}{ Comment } \\
\hline 6 & 0.58 & 0.68 & $\begin{array}{l}\text { Union of Lublin. This } P \text { is quite well defined. Two tollhouses } \\
\text { indicate that it used to be the administrative border of the city. } \\
\text { This results in } P_{6} \text { being a major communication node with heavy } \\
\text { vehicular traffic. Despite the urban attractiveness, these } \\
\text { circumstances make it less pleasant for the visitors. }\end{array}$ \\
\hline 13 & 0.83 & 0.65 & $\begin{array}{l}\text { Piazza Arringo. Due to the proportions in plan, this } P \text { can } \\
\text { viewed as a widened street. It does not form a well defined } \\
\text { coherent space. However, due to the beauty and harmony of } \\
\text { the surrounding architecture, as well as the usage of urban } \\
\text { compositional elements (e.g. two fountains), } P_{13} \text { is an exquisite }\end{array}$ \\
\hline
\end{tabular}




\begin{tabular}{|c|l|l|l|}
\hline & & & public space. \\
\hline 11 & 0.87 & 0.76 & $\begin{array}{l}\text { Praca Dom Pedro IV. This place has been one of the main } \\
\text { squares in Lisbon since the Middle Ages. It is very large, which } \\
\text { resulted in lower NP PER rating. However, the size fits well the } \\
\text { population demand which is not included in AGE. Moreover, } \\
\text { P }_{11} \text { is masterpiece of classical monumental urban space. }\end{array}$ \\
\hline 14 & 0.85 & 0.76 & $\begin{array}{l}\text { Heian Jingu. The plan of } \mathrm{P}_{14} \text { is somewhat complicated. } \\
\text { However the urban composition, placement of plants and } \\
\text { presence of wooden architecture makes this place very } \\
\text { attractive. }\end{array}$ \\
\hline 18 & 0.63 & 0.57 & $\begin{array}{l}\text { Zocalo. } \mathrm{P}_{18} \text { is extremely large. In this study it is the maximum } \\
\text { size reference for rescaling the property of smallness. } \\
\text { Nevertheless it is the main square in central Mexico City, one of } \\
\text { the most populated cities in the World. Thus, its size seems } \\
\text { quite relevant. }\end{array}$ \\
\hline 17 & 0.63 & $\begin{array}{l}\text { Potsdamer Platz. P }{ }_{17} \text { in the present form has been completed in } \\
\text { the late 1990s. Despite its under-defined form it is an attractive } \\
\text { social place in Berlin. }\end{array}$ \\
\hline
\end{tabular}

\section{Discussion}

The quality of the plazas considered in this paper may not be representative worldwide; however, they should be considered as a benchmark for urban composition. Some of these plazas are among the best in the world, and thus even the "fair" ones are in fact of rather high quality. All of them have a strong historical background and most of them evolved over centuries.

One of the principles of public square design is the relationship to the assumed number of users. This parameter has not been captured by the simple model for AGE. At the present stage, AGE focuses on the geometrical properties of a plaza, which can be calculated directly from its plan . However, it is straightforward to include that parameter, providing that the relevant data is available.

Moreover, the smallness parameter seems oversimplified, as it proportionally assesses the "goodness" of a size based on two arbitrarily chosen plazas. The inclusion of the aforementioned population parameter would make the smallness parameter more rational.

The model presented does not include architectural aspects of a plaza. Although it seems that even such a simple model gives meaningful evaluation of a plaza's quality, the exceptions shown in Table 9 indicate that the architectural quality of surrounding buildings has a strong positive influence on the perception of a public space. Nevertheless, the intention of this paper is to provide a robust and simple method for evaluating a given space for possible improvements, not for absolutely precise evaluation of a given plaza. The latter seems neither possible, nor necessary. 
It would be desirable if the regularity could also be assessed automatically, rather than through arbitrary judgment, as is done at present. However, this problem seems particularly difficult and a universal solution seems unachievable. Nonetheless, a systematization of this judgment is presently under consideration.

In this paper the responses evaluating plaza qualities have been accumulated to a single number by simple summation and normalization to the range $0-1$. This model is most likely oversimplified. However, determination of the interdependencies among the qualities and their relative importance seems a very challenging problem, and is not part of this study. However, with a more realistic formula for HSE, it is conceivable to find a formula for AGE which would fit HSE more closely. Since at the present stage such accuracy in HSE in unavailable, the model for AGE was kept as simple as possible.

At the present stage, a certain degree of "manual" work is necessary to determine the elements for calculations of $S C E$ and $R$. This process could be, at least partially, automated. However, full automation based on a single plan or aerial photograph is not presently conceivable. The reason is that even the most advanced available methods [14] are not fully reliable, usually due to the radiometric similarity between building roofs and the image background.

\section{Conclusions}

Based on 19 worldwide plazas, automated geometrical evaluation (AGE) of urban spaces introduced in this paper shows good agreement with human subjective evaluation (HSE). AGE is based on three geometrical properties derived from a plaza's plan: namely, smallness, enclosure, and regularity. Compactness has also been considered; however, it seems not to be relevant for this model.

This paper focuses on basic two-dimensional information of a plaza. However, since human perception is spatial, not planar, and gathering three-dimensional information about urban space [15] is becoming easier, the natural direction for the future study for a more accurate AGE model would be three-dimensional.

\section{Acknowledgments}

This work was completed as part of the Singapore University of Technology \& Design and Massachusetts Institute of Technology Postdoctoral Fellows Program (SUTD-MIT PDP). The research is titled: "Effective computational methods for grid and rasterbased modeling of practical problems in architectural and urban layout design".

Dr. Alan Brayne is gratefully acknowledged for the proofreading.

\section{References}

[1] M. Zawidzki, T. Nagakura, B. Tunçer, "Preliminary Results of the Town Square Evaluation Method based on Digitized Plan Processing", in P. Iványi, B.H.V. Topping, (Editors), "Proceedings of the Ninth International Conference on 
Engineering Computational Technology", Civil-Comp Press, Stirlingshire, UK, Paper 92, 2014. doi:10.4203/ccp.105.92

[2] S. Perovic, N. Kurtovic Folic, "Visual Perception of Public Open Spaces in Niksic", Procedia - Social and Behavioral Sciences, Volume 68, pp. 921-933, 2012.

[3] N. Taylor, "Legibility and Aesthetics in Urban Design", Journal of Urban Design, 14(2), 189-202, 2009.

[4] C. Sitte, "City Planning According to Artistic Principles", 1889, in "Camillo Sitte: The Birth of Modern City Planning", (Transl. G.R. Collins and C.C. Collins), Rizzoli New York, 1986.

[5] Alexander, Christopher and Ishikawa, Sara and Silverstein, Murray, A pattern language: towns, buildings, construction, Oxford University Press, 1977.

[6] List of city squares by size, Wikipedia. https://en.wikipedia.org/wiki/List of city squares by size

[7] E. Bribiesca, "An easy measure of compactness for 2D and 3D shapes", Pattern Recognition, 41(2), 543-554, 2008.

[8] D.H. Ballard, C.M. Brown, "Computer Vision", Prentice-Hall, Englewood Cliffs, NJ, 1982.

[9] J. Bogaert, R. Rousseau, P. Van Hecke, I. Impens, "Alternative area-perimeter ratios for measurement of 2D shape compactness of habitats", Applied Mathematics and Computation, Volume 111(1), 71-85, 2000.

[10] G. Piccioli, E. De Micheli, P. Parodi, M. Campani, Robust method for road sign detection and recognition, Image and Vision Computing, Volume 14, Issue 3, April 1996, Pages 209-223

[11] Barnes, N.; Loy, G.; Shaw, D.; Robles-Kelly, A., "Regular polygon detection", Computer Vision, 2005. ICCV 2005. Tenth IEEE International Conference on , vol.1, no., pp.778,785 Vol. 1, 17-21 Oct. 2005, doi: 10.1109/ICCV.2005.207

[12] Aloupis, Greg, et al. "Detecting all regular polygons in a point set." arXiv preprint arXiv:0908.2442 (2009).

[13] Ramon Chalmeta, Ferran Hurtado, Vera Sacristán, Maria Saumell, Measuring regularity of convex polygons, Computer-Aided Design, Volume 45, Issue 2, February 2013, Pages 93-104, ISSN 0010-4485, http://dx.doi.org/10.1016/j.cad.2012.07.012.

[14] Salman Ahmadi, M.J. Valadan Zoej, Hamid Ebadi, Hamid Abrishami Moghaddam, Ali Mohammadzadeh, Automatic urban building boundary extraction from high resolution aerial images using an innovative model of active contours, International Journal of Applied Earth Observation and Geoinformation, Volume 12, Issue 3, June 2010, Pages 150-157, ISSN 0303-2434, http://dx.doi.org/10.1016/i.jag.2010.02.001.

[15] Philipp Meixner and Franz Leberl, 3-Dimensional Building Details from Aerial Photography for Internet Maps, Remote Sens. 2011, 3(4), 721-751;

doi:10.3390/rs3040721 